\title{
Amino Acid, Peptide, or Protein
}

National Cancer Institute

\section{Source}

National Cancer Institute. Amino Acid, Peptide, or Protein. NCI Thesaurus. Code C232.

A class of molecules that includes amino acid monomers and amino acid polymers, of any length, linked by covalent peptide bonds. 